\title{
Viewpoint Enabling circular supply chains in a high-tech manufacturing industry
}

\section{Introduction}

Over the past few years, much has been said about the potential of $\mathrm{CE}$ in contributing and achieving sustainability goals (Geissdoerfer et al., 2018), as well as the post-coronavirus disease 2019 (COVID-19) green policies and smarter business models in particular (Kamal, 2020; Schröder, 2020). And yet, we can still observe that a range of major high-tech industries, even those as advanced technologically as the electronics manufacturing, have not fully embraced CE in their global operations. Indeed, these industries have gone some way towards the adoption of recycle, reuse and reduction (3R) principles by attempting to structure their production around the reverse logistics and closed-loop supply chains (CLCSs). However, the latter remain predominantly fragmented and, crucially, are mostly restricted to channelling the downstream flow of used or obsolete equipment to its original manufacturers (Ashby, 2018). At the same time, the real paradigm shift towards CE can only happen with "opening the loops", i.e. introducing the CSCs capable of recovering value from the used items through redirecting their downstream flow to the alternative manufacturers, even those from other sectors, rather than to their sources of origin only (Farooque et al., 2019). Essentially, CSC represents an eco-system which goes beyond 3R and extends the life of used/obsolete products through remanufacture and repurpose - key amongst the extra "Rs" on top of mere recycle/reuse.

So why have many high-tech industries thus far been unable or reluctant to take advantage of CSC and even CLSC to a large extent? In our view, the success of CSC implementation is fundamentally determined by the information- and knowledge-sharing capabilities amongst the supply chain players. The latter, however, have been historically confronted with a number of barriers which can mostly be attributed to information deficits, knowledge asymmetry and the associated uncertainty within the supply chains (e.g. Cragg and McNamara, 2018; Sundram et al., 2018; Ochoa et al., 2017; Irani et al., 2017). In an attempt to address these issues, we report on a novel approach to enabling CSC in high-tech manufacturing based on a global trading exchange platform supporting the aftermarket processes in a secure collaborative environment. In addition to overcoming the aforementioned information/knowledge management barriers and opening the loop towards CSC, the proposed platform is equipped with functionality resolving the demandsupply timing gap (i.e. supply holding until demand materialises), which currently has no efficient way of handling other than by long-term storing items until they can be re-used. Furthermore, the proposed solution features a virtual bundling of items, which addresses a requirement to source more than a single piece of equipment at a time to meet specifications (Leszczyc and Häubl, 2010). The latter task is currently shown to be laborious and exacerbated by inaccurate data on equipment and associated processes evident in many organisations (Jaeger and Upadhyay, 2020).

The proposed platform is furthermore prototyped and applied for the proof of concept to the semiconductor manufacturing as a typical global high-tech manufacturing industry.

The authors would like to thank Wisetek (Ireland-USA) and AdaptiveHVM (Ireland) for creating a supportive and innovation-oriented environment for completing this research.

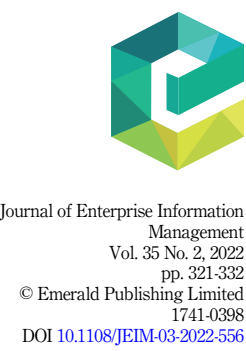


JEIM

35,2

322

With this approach, we aim to add value to the industry's major supply chain players which comprise the independent device manufacturers (IDMs), original equipment manufacturers (OEMs) and third-party service providers (Hickey and Kozlovski, 2020). The semiconductor IDM includes such notable names as Intel whereas Applied Materials and Lam Research are amongst the industry's OEM. Overall, the market for primary semiconductor equipment was US\$59.8bn in 2019 (Davis, 2020), whilst the visible aftermarket for secondary equipment and spare parts is estimated to be worth several billion dollars annually (Gates et al., 2013; SEMI, 2020). Although rooted in the semiconductor equipment manufacturing, the solution reported on in the remainder of this paper can be argued to be extendable to the entire electronics industry and across a range of the high-technology spectrum.

\section{The proposed system approach}

\subsection{Support for the shared reverse logistics}

A shared reverse-logistics process incorporating an industry-sponsored marketplace enhanced with a trusted knowledge-sharing environment was shown to benefit aftermarket operations for the semiconductor industry (Hickey and Kozlovski, 2020; Bahinipati and Deshmukh, 2012). The system approach proposed here embeds such a process in a global trading exchange and takes a step further by supporting cross-industry logistics decisions. With this approach, transportation costs can be addressed via the minimisation of resources through effective information exchange between participants of the platform. Economies of scale would also apply because the system will aggregate the total global supply and demand enabling unit cost reductions. Furthermore, the supply and demand uncertainty through time gaps (Hickey and Kozlovski, 2020) can be reduced via the global exchange structure allowing vendors to see existing and future demand needs and remanufacturing/repurpose opportunities. In particular, buyers can signal intentions to purchase future items or kits of items as if they would place purchase orders in a normal primary market set up. A typical example would be a preventive maintenance bundle where a number of non-homogeneous parts and consumables are needed to complete a task. It is common to see this happen in primary use situations but difficult to find any evidence of its use outside of individual firm reuse programmes in global CSC scenarios (Ramírez et al., 2018).

\section{2 e-marketplace design}

The design method was enhanced with a combination of soft systems methodology and thematic analysis guiding the exploration of real world and systems world issues, elicitation of requirements and identification of system's features based on interviewing a diverse range of experts from different organisations within the industry (Checkland and Poulter, 2020). A use-case diagram is shown in Figure 1 using the Unified Modelling Language (UML). Figure 2 provides an overview of the system's blocks, which are based on the use cases captured in Figure 1, whilst streamlining the semiconductor aftermarket operations. The backbone of the system gathers data from vendor participants (1) and uploads to a central storage and display location (2).

The search and match module (3) is the central part of the system providing buyers and sellers with decision support based on a set of rules, which essentially include those on immediate and potential remanufacturing and reuse opportunities. Whilst the initial set can include just a few rules, it can be continuously expanded and refined based on machine learning principles. It also allows the creation of virtual bundles enabled from (9) when a buyer needs to purchase more than one item. At the moment, buyers do not ordinarily use the secondary market for project work which tends to use kits or bundles of parts because the search time is too long and hence the need for an automated bundling approach (Hickey and 


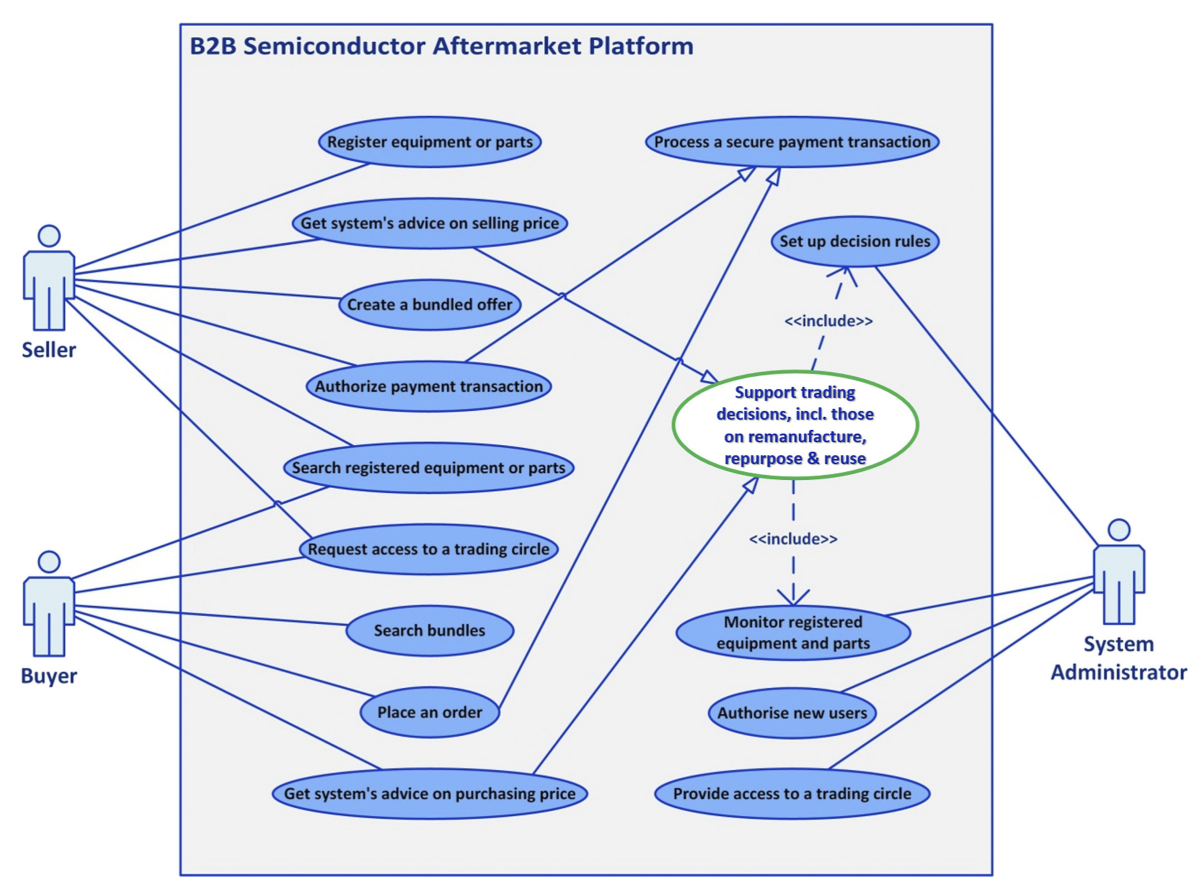

Viewpoint

323

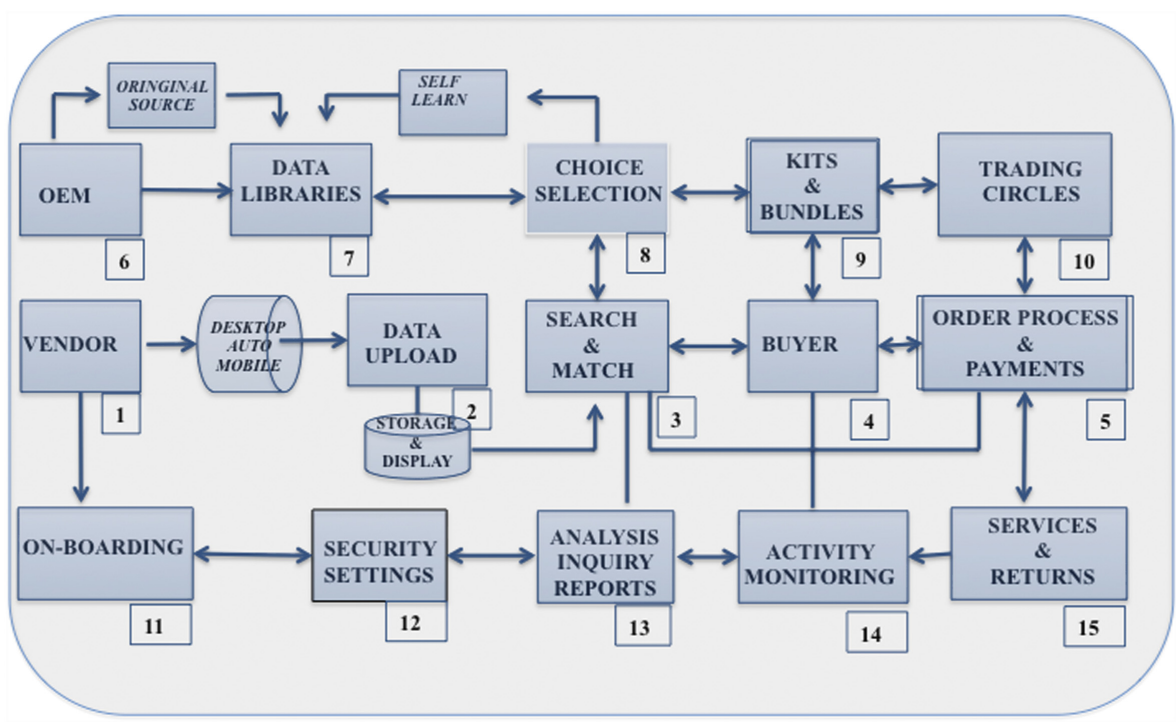

Figure 2. Block diagram of proposed system

Kozlovski, 2020). Trading circles (10) address the competitive advantage issues through defined inclusive or exclusive trading partner relationships. The on-boarding process (11) comprises two modules, authentication (11) and security settings (12). The OEM link provides 
JEIM

35,2

324

an original source of reference and the self-learning capability again improves matching using selections made in real time (8). In situations where buyers cannot make a selection decision due to its unavailability, this part of the system will prompt the buyer to create either a wish list or watch list. QA and activity monitoring (14), on top of transaction logging and audit trail maintenance, also monitors for issues such as multi-marketing or quality of service feedback and acts as a collection point for issues requiring escalation. The analysis, inquiry and reporting (13) module is the window to individual and aggregate activity on the system. The specific interactions between the equipment buyer, seller and the system in the trading process, which is capable of supporting bundling through pre-defined decision rules, is depicted in Figure 3.

\subsection{Trading process support}

The general conclusion arising from research of CSCs in the semiconductor manufacturing is that there is significant room for improvement in its aftermarket (Hickey and Kozlovski, 2020). Specifically, the trading activity is clustered with no single trading exchange that is large enough to capture activity on a worldwide basis. Hence, there exists as an entrepreneurial opportunity in the market (Bahinipati and Deshmukh, 2012). The aftermarket is not subject to widespread OEM control, as one would expect to see in a CLSC (Cohen and Winn, 2007). Significant third-party competition has grown over the years as OEMs chase Moore's law to maintain competitive advantage for next-generation technologies (Mack, 2011). The practical implications of the proposed system as they relate to the question under investigation are that the effectiveness and efficiency of the aftermarket can be improved if certain measures are taken.

These measures include the creation of a shared information environment with mediated access control to allow information deficits relating to technical and other information to be remedied. Mediated access control will assure that the original title owners of the information retain control over commercial access whilst enabling third parties to tender commercially viable partner solutions. A second key initiative involves the creation of a shared reverselogistics approach as discussed in Section 2.1. This will create economies of scale especially for smaller OEMs and third-party players to significantly reduce transaction costs. At a practical level, this could commence with an information-sharing arrangement between companies who can benefit from knowing what equipment is available and what is becoming available in the reverse logistics pipeline. This would then be extended to sharing warehousing and logistics resources in a way that optimises the benefit to each member of the cooperating group. A third key measure involves the creation of a global B2B aftermarket exchange, which would link to the first two measures. The exchange could take the form of an industry-sponsored approach. This is needed because SEMI, which is the global semiconductor association, tends to be a customer-driven organisation (SEMI, 2020) so the initiating action for such an exchange should come from its members within the industry. The presented approach provides a robust platform on which to base justification for such an action.

Such an approach would enable real-time market information to be made available, creating a transparent global trading platform for activities in the semiconductor aftermarket. It would significantly reduce the transaction costs associated with searching and matching for reuse/remanufacture/repurpose, administration and marketing and support open innovation (Chung and Lee, 2020). But the viability of these proposals depends on the willingness of competitors to collaborate. Semiconductor industry participants have a demonstrated track record of collaboration amongst competitors. Specifically, it can be recommended that the Semiconductor Equipment Association wing of SEMI initiate a round table proposal discussion on the merits of creating the global exchange platform proposed in this paper. This group carries the responsibility for effective and 


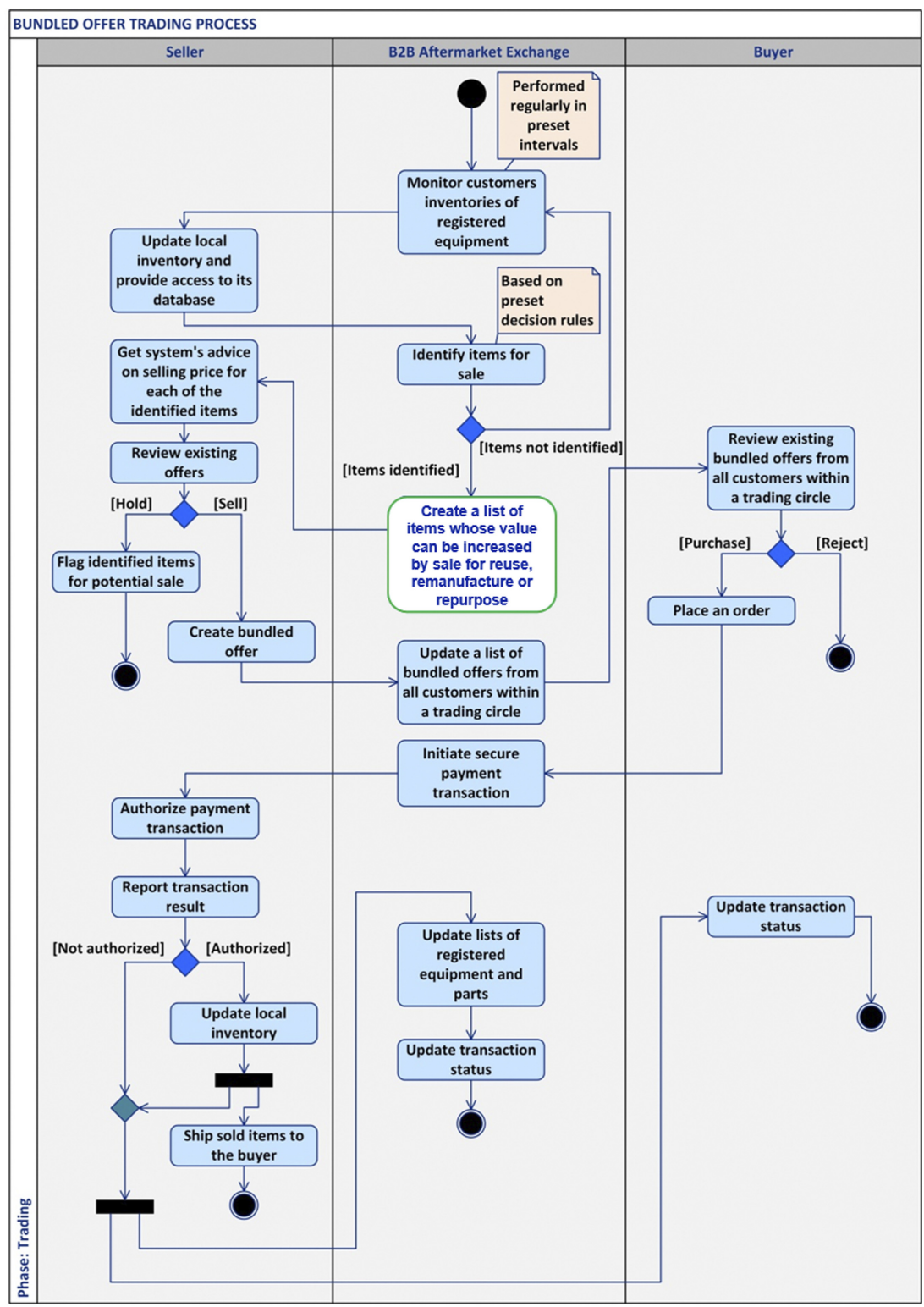

Viewpoint

Figure 3.

UML activity diagram for a bundled offer trading process

efficient functioning of the secondary market on SEMI's behalf and would be able to facilitate proper consultation on the approach detailed in this paper.

\section{Prototyping the system}

Having established the basic system requirements as described earlier, the work commenced on building a mock-up of the global exchange. The initial phase involved creating a UI/UX 
JEIM

35,2

326

representing input/output parameters for key features of the global exchange. It then moved to a more detailed specification where data flows, file structures and processing logic were established. From here, the work moved into a preliminary coding phase where one began to see the system's interface in action. At this point, progress was reviewed with an advisory team which comprised representatives of the potential user community and feedback taken on board to enhance the functional features of the prototype. Second and third development cycles were concluded before the system began to exhibit the potential to deliver the requirements identified in the previous sections, whilst maintaining the balance and connection between the information and physical worlds (McElroy, 2016). The prototype functionality is further illustrated in Figure 4 as follows. Figure 4(a) is a snapshot of the home landing page. It contains a series of tile selections that allows a user to set up a storefront, for example, which is the supply line for the exchange. A company can load their used equipment and parts for sale to the system from this tile icon. There are three ways to load, namely (1) manually, (2) automatically from a manifest or spreadsheet and (3) using a field device such as a mobile phone. The "Manage Inventory" tile allows storefront owners to manage and adjust inventory already on the exchange that belongs to them, whilst the "Trading Circles" tile enables closed trading loops to be established between participants in the exchange.

Figure 4(b) shows the search screen. The search function parses multiple levels of technical attributes including engineering revision levels and other unique details such as where used for items, where issues such as contamination or exposure to certain materials or gases are vital aspects of the search capability. Figure 4(c) gives an example of a "Trading Circles" screenshot. This feature enables closely knit companies to create a private trading group within the wider exchange. It also facilitates sensitivities where IP is an issue. The "Bundles" feature in Figure 4(d) allows sellers to set up bundles or combinations of items for sale in bulk quantity whilst providing buyers to search for specific bundles or kits they need to fulfil specific tasks such as preventative or shutdown maintenance. It also enables future time needs to be set up. It means that a buyer can enter a wish list for a future purchase (e.g. "shutdown maintenance in six month" time) and the system will assemble the bundle in virtual reality as it becomes available and will then notify the buyer. This addresses the timing gap between demand and supply (Hickey and Kozlovski, 2020) which is a significant source of uncertainty inhibiting effective use of the aftermarket and the $\mathrm{CE}$. One of the annoying things about secondary markets is that items are often not available when one needs them. If, however, one plans ahead then the items can be assembled over time as they become available. Figure 4(d) provides a screenshot of a bundle configuration.

\section{Research findings}

Table 1 summarises findings allowing the system design to address the collaboration challenges, system requirements and security concerns discussed in Sections $1-3$. Whilst the research outcomes strongly support existing literature on privacy and security issues relating to e-markets and e-exchanges generally, they further emphasise requirements relating to the independence of the e-market where power concentration and relationships are not allowed to cause bias (Chang and Wong, 2010).

\section{Conclusions}

\subsection{Novelty of the proposed solution}

It is expected that the proposed system approach discussed in this paper will offer a range of unique benefits to the high-tech industrial players through enabling CSC and, crucially, providing them with an eco-system ensuring a recovery of value and extended life for 
Viewpoint

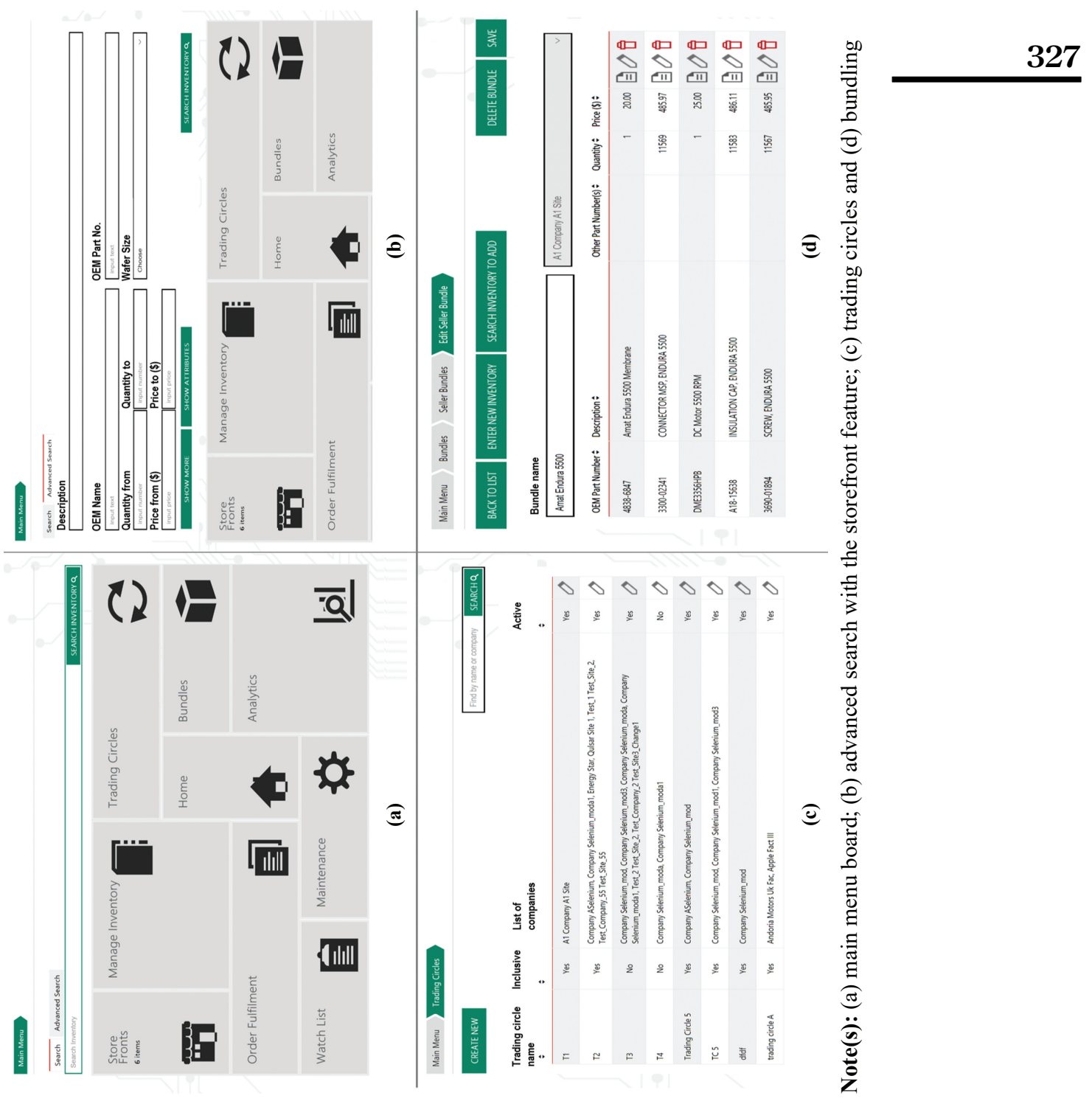

Figure 4. Functional overview 
JEIM

35,2

\section{8}

\begin{tabular}{lll}
\hline Identified collaboration challenge & Proposed design features & References \\
\hline Independence, privacy and security & $\begin{array}{l}\text { Independent ownership, secure trading circles } \\
\text { and authenticated user community }\end{array}$ & $\begin{array}{l}\text { Chang and Wong } \\
\text { (2010) }\end{array}$ \\
Lack of transparency & $\begin{array}{l}\text { Global information system; aggregated data } \\
\text { analysis showing complementarities, }\end{array}$ & $\begin{array}{l}\text { Bahinipati and } \\
\text { Deshmukh (2012) }\end{array}$
\end{tabular}

substitutes etc. and real-time data availability supported by multi-site, multi-item search and matching

User-defined kits and bundles, community access to common kits and bundles within security defined settings

Third-party competition

Opportunity for OEMs to collaborate closely with trusted partners and develop better reverse logistics processes

Data accuracy, consistency and ease of data upload to reduce administrative overhead

Reference libraries developed from original

OEM sources and self-learning via real-time transactional data and ease of data upload with online validation against reference sources

Scope and quality issues

Eight basic categories of data required; source validation on quality of data using libraries. Online help to re-create missing information from library databases

Alerts and timeliness in recognising aftermarket opportunities

Ease of data upload reduces overhead and costs improving the chances that time value decay will be reduced; easier to monitor aggregate demand and see opportunities earlier and use of wish lists and watch lists to pull future demand forward and enable earlier response

Table 1.

Summarising the findings on the platform's challenges and requirements addressed in the proposed system design
Classification and description issues

Infrastructure

User authentication

Terms and conditions of service
Access to library reference data and self-

learning capability

Secure cloud infrastructure

Formal on-boarding process

Formal user agreement, escalation and dispute resolution and formal sanction process up to and including removal
Leszczyc and

Häubl (2010)

Zink and Geyer

(2017)

Hickey and

Kozlovski (2020)

$\mathrm{Xu}(2012)$

Hickey and

Kozlovski (2020)

Jajodia et al. (2014)

Jajodia et al. (2014)

McElroy (2016)

McElroy (2016)

functional items that are presently disposed of or placed in long-term storage awaiting reuse (Hickey and Kozlovski, 2020). Figure 5 illustrates this concept by depicting an example of a used item circulating through various OEMs and third-party providers which recover its value.

In this example, the recovery is first achieved by diverting the item via CSC to remanufacture/repurpose in a different industrial sector, then via CLSC to the same OEM for reuse and subsequently via CSC to another sector again. In the semiconductor context, the latter can represent, for instance, redeployment of obsolete equipment previously used for producing high-end microprocessors (e.g. those for data centres) in a consumer segment requiring wafers with slower processing power (e.g. IoT). As shown in Figure 5, the equipment remanufacture or refurbishment can be completed by alternative OEMs rather than the initial one and more importantly by the third-party providers plugged into the envisioned business model. Whilst such supply loops have not been fully opened yet, the prototyping of the system we report on has effectively shown the potential of orchestrating and supporting the related CSC processes on a global scale. 


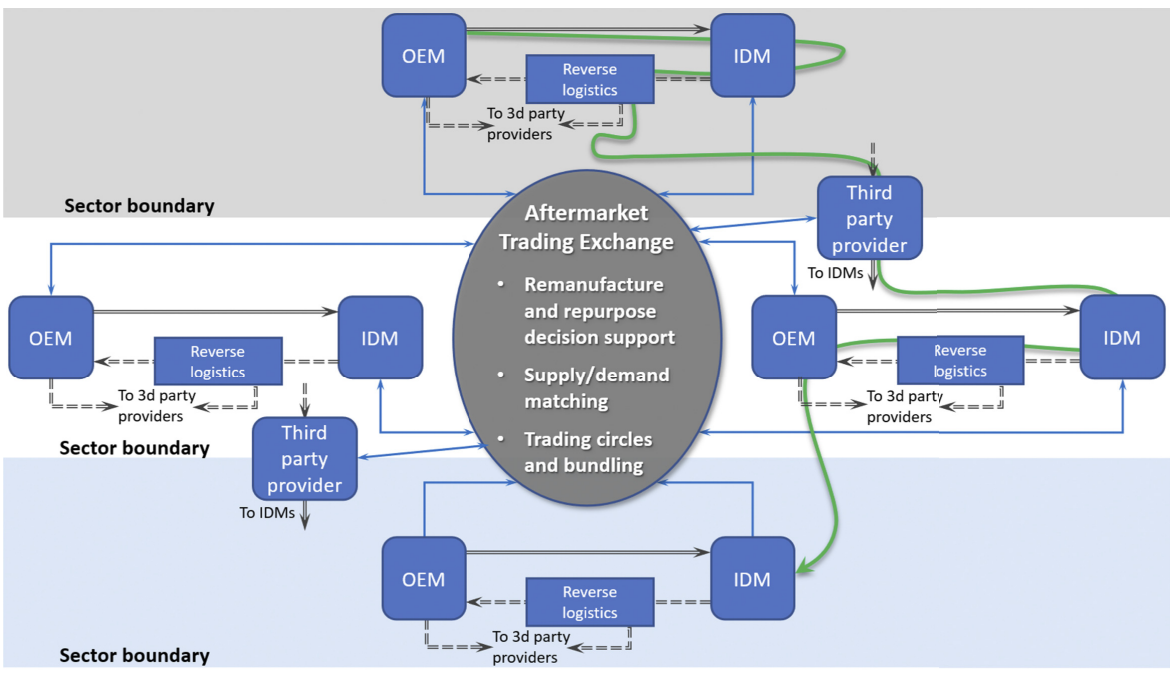

Key:

Information flows

Upstream physical flows

$====$ Downstream physical flows (shared reverse logistics)

_ Example of a CSC physical path of a used and value-recovered item traversing different OEMs and industrial sectors

\subsection{Lessons learnt}

Whilst the proposed platform has addressed many of the core issues associated with CSCs in the global semiconductor manufacturing, many practical implementation issues have surfaced during the prototyping process. The major lessons learnt are summarised in Table 2.

\begin{tabular}{|c|c|c|c|}
\hline Implementation issue & Lesson & $\begin{array}{l}\text { Consequences and actions } \\
\text { arising }\end{array}$ & References \\
\hline $\begin{array}{l}\text { Perceived value concerns } \\
\text { about aftermarket/secondary } \\
\text { market parts and equipment }\end{array}$ & $\begin{array}{l}\text { Transaction cost and } \\
\text { quality verification concerns } \\
\text { inhibit large scale use of } \\
\text { aftermarket parts, even for } \\
\text { new in-box product }\end{array}$ & $\begin{array}{l}\text { Enable transaction cost } \\
\text { reduction through online } \\
\text { bundling and shared } \\
\text { logistics and fix the quality } \\
\text { concerns through virtual/ } \\
\text { physical verification }\end{array}$ & $\begin{array}{l}\text { Leszczyc and } \\
\text { Häubl (2010) }\end{array}$ \\
\hline $\begin{array}{l}\text { Shared technical information } \\
\text { is not available on a wide } \\
\text { scale }\end{array}$ & $\begin{array}{l}\text { OEM suppliers have } \\
\text { traditionally held } \\
\text { information tightly for } \\
\text { competitive purposes }\end{array}$ & $\begin{array}{l}\text { Participation in a global } \\
\text { partnership arrangement } \\
\text { would most likely increase }\end{array}$ & $\begin{array}{l}\text { Hickey and } \\
\text { Kozlovski } \\
(2020)\end{array}$ \\
\hline $\begin{array}{l}\text { Network connectivity. How } \\
\text { to make all aftermarket parts } \\
\text { and equipment visible on a } \\
\text { shared platform }\end{array}$ & $\begin{array}{l}\text { Multiple user platforms and } \\
\text { varying levels of security } \\
\text { policies and configuration } \\
\text { would make it a difficult } \\
\text { task to connect everyone }\end{array}$ & $\begin{array}{l}\text { Requires further research; } \\
\text { however, similar issues have } \\
\text { been resolved with } \\
\text { structured batch file transfer } \\
\text { and applications program } \\
\text { interface solutions }\end{array}$ & $\begin{array}{l}\text { McElroy } \\
(2016)\end{array}$ \\
\hline
\end{tabular}

Viewpoint

Figure 5. The proposed solution as CSC enabler 
JEIM

35,2

330

\subsection{Implications to theory and practice}

Theoretical implications of this work include the identification of an information management model ensuring the improved market effectiveness and efficiency as a result of the ability of demand and supply to see each other in a transactional sense. The technical complexity of many non-commoditised parts in the area under study requires a new approach for enabling transactional exchange between the global semiconductor manufacturers, which is presented in this paper as the proposed platform. Furthermore, this case study contributes to understanding of CSC as well as associated challenges in high-tech industries, thereby formulating the design principles of an intelligent collaborative information system for secondary equipment. An increased level of the aftermarket exchanges arising from this approach will increase remanufacture/repurpose whilst reducing reuse/recycling, thus representing $\mathrm{CE}$ facilitation economy in semiconductor manufacturing and wider electronics industry. Furthermore, as it has a potential to facilitate and expand business networks, the study contributes to the body of knowledge on inter-organisational performance and quality management (Urbański et al., 2020). On a practical level, this case study demonstrates marketplace architecture that is capable of integrating the aftermarket into the global supply chains. As such, it can be considered as a platform that can be effectively deployed to support and stimulate third-party businesses involved in remanufacture, refurbishment and repair. This is an important element in the objectives of sustainability and the reduction of carbon footprint, especially critical for the post-pandemic economic recovery (Hepburn et al., 2020).

\subsection{Limitations and future research}

Whilst the primary research was conducted in the semiconductor industry, it appears that the issues and findings are similar across many high-tech sectors. It seems that the complexity varies with the degree of commoditisation. For example, the information technology asset disposition industry suffers from similar issues but many of the products are commodities. It is a limitation of the original research that it did not undertake more detailed analysis of the different sectors within high technology as this would have given a better sense of how generalisable the solution might be. Future research is needed to develop an understanding of how our vision can be applied in a more unified way across the global electronics industry. The bundling functionality supported by the presented design can be further extended to include maintenance services as part of bundle offers. This could become a vehicle for implementing novel servitisation-based and data-philanthropy-based business models whilst solving the associated challenges (Kamal et al., 2020; Kühl et al., 2019). Such solutions would be crucial for the global economic recovery and sustainable supply chains discussed earlier. The supply chain strategies were shown to be a key to the social and environmental sustainability (Kot et al., 2019a, b). Therefore, the need to offer greener tools and methods allowing us to reuse, repurpose and remanufacture high-tech products has never been greater (Liakos et al., 2019). This paper offers a way forward to extend the lifecycle into CSC of many high-tech products that need to overcome issues similar to those of the semiconductor products, which defines a new and timely research area.

Patrick Hickey

Dublin Centre for European Strategy, Dublin, Ireland

Muhammad Mustafa Kamal

Coventry University, Coventry, UK, and

Eugene Kozlovski

Dublin Centre for European Strategy, Dublin, Ireland and University of Wales Trinity Saint David, London Campus, Carmarthen, UK 


\section{References}

Ashby, A. (2018), "Developing closed loop supply chains for environmental sustainability", Journal of Manufacturing Technology Management, Vol. 29 No. 4, pp. 699-722.

Bahinipati, B.K. and Deshmukh, S.G. (2012), "Vertical collaboration in the semiconductor industry: a decision framework for supply chain relationships", Computers and Industrial Engineering, Vol. 62 No. 2, pp. 504-526.

Chang, H.H. and Wong, K.H. (2010), "Adoption of e-procurement and participation of e-marketplace on firm performance: trust as a moderator", Information and Management, Vol. 47 No. 5 , pp. 262-270.

Checkland, P. and Poulter, J. (2020), "Soft systems methodology", Systems Approaches to Making Change: A Practical Guide, Springer, London, pp. 201-253.

Chung, E. and Lee, K. (2020), "The necessity of anterior knowledge exchange activities for technological collaboration and innovation performance improvement", International Journal of Technology Management, Vol. 82 No. 1, pp. 66-96.

Cragg, T. and McNamara, T. (2018), "An ICT-based framework to improve global supply chain integration for final assembly SMES”, Journal of Enterprise Information Management, Vol. 31 No. 5 , pp. 634-657.

Davis, S. (2020), “2019 Global Semiconductor sales slip 7 per cent to \$59.8Bn”, Semiconductor Digest, available at: https://www.semiconductor-digest.com/2020/04/14/2019-global-semiconductorequipment-sales-slip-7-percent-to-59-8-billion-semi-reports/ (accessed 25 May 2020).

Farooque, M., Zhang, A., Thürer, M., Qu, T. and Huisingh, D. (2019), "Circular supply chain management: a definition and structured literature review", Journal of Cleaner Production, Vol. 228, pp. 882-900.

Gates, J.T., Johnson, D. and McDaniel, D. (2013), "Managing legacy fabs and the role of after equipment, solid state technology", available at: http://electroiq.com/blog/2013/10/managinglegacy-fabs-and-the-role-of-after-equipment (accessed 15 November 2013).

Geissdoerfer, M., Morioka, S.N., de Carvalho, M.M. and Evans, S. (2018), "Business models and supply chains for the circular economy”, Journal of Cleaner Production, Vol. 190, pp. 712-721.

Hepburn, C., O'Callaghan, B., Stern, N., Stiglitz, J. and Zenghelis, D. (2020), "Will COVID-19 fiscal recovery packages accelerate or retard progress on climate change?”, Smith School Working Paper 20-02, available at: https://smithschool.ox.ac.uk/publications/wpapers/workingpaper2002.pdf (accessed 6 September 2020).

Hickey, P. and Kozlovski, E. (2020), "E-strategies for aftermarket facilitation in the global semiconductor manufacturing industry", Journal of Enterprise Information Management, Vol. 33 No. 3, pp. 457-481.

Irani, Z., Kamal, M.M., Sharif, A. and Love, P.E.D. (2017), "Enabling sustainable energy futures: factors influencing green supply chain collaboration”, Production Planning and Control, Vol. 28 Nos 6-8, pp. 684-705.

Jaeger, B. and Upadhyay, A. (2020), "Understanding barriers to circular economy: cases from the manufacturing industry”, Journal of Enterprise Information Management, Vol. 33 No. 4, pp. 729-745.

Jajodia, S., Kant, K., Samarati, P., Singhal, A., Swarup, V. and Wang, C. (2014), Secure Cloud Computing, Springer, New York.

Kamal, M.M. (2020), "The triple-edged sword of COVID-19: understanding the use of digital technologies and the impact of productive, disruptive, and destructive nature of the pandemic", Information Systems Management, Vol. 37 No. 4, pp. 310-317.

Kamal, M.M., Sivarajah, U., Bigdeli, A.Z., Missid, F. and Koliousis, Y. (2020), "Servitization implementation in the manufacturing organisations: classification of strategies, definitions, benefits and challenges", International Journal of Information Management, Vol. 55, p. 102206. 
Kot, S., Haque, A.U. and Kozlovski, E. (2019a), "Mediating effect of strategic supply chain management on social and environmental sustainability: evidence from SMEs of Canada, Iran and Turkey", International Journal of Supply Chain Management, Vol. 8 No. 6, pp. 105-117.

Kot, S., Haque, A.U. and Kozlovski, E. (2019b), "Strategic SCM's mediating effect on the sustainable operations: multinational perspective”, Organizacija - Journal of Management, Informatics and Human Resources, Vol. 52 No. 3, pp. 219-235.

Kühl, C., Bourlakis, M., Aktas, E. and Skipworth, H. (2019), "How does servitisation affect supply chain circularity? - a systematic literature review", Journal of Enterprise Information Management, Vol. 33 No. 4, pp. 703-728.

Leszczyc, P.T.P. and Häubl, G. (2010), "To bundle or not to bundle: determinants of the profitability of multi-item auctions", Journal of Marketing, Vol. 74 No. 4, pp. 110-124.

Liakos, N., Kumar, V., Pongsakornrungsilp, S., Garza-Reyes, J.A., Gupta, B. and Pongsakornrungsilp, P. (2019), "Understanding circular economy awareness and practices in manufacturing firms", Journal of Enterprise Information Management, Vol. 32 No. 4, pp. 563-584.

Mack, C. (2011), "Fifty years of moore's Law", IEEE Transactions on Semiconductor Manufacturing, Vol. 24 No. 2, pp. 202-206.

McElroy, K. (2016), Prototyping for Designers: Developing the Best Digital and Physical Products, O'Reilly Media.

Ochoa, O.L., Claes, B., Koryak, O. and Diaz, A. (2017), "Integration through orchestration. The interplay between enterprise systems and inventory management capabilities", Journal of Enterprise Information Management, Vol. 30 No. 4, pp. 555-582.

Ramírez, J.D., Vera, P.P. and Martínez, A.G. (2018), "Improvement of material supply system through kitting concept and IT solutions", Proceedings of the North American Conference in Industrial Engineering and Operations Management, pp. 695-704.

Schröder, P. (2020), Why an Inclusive Circular Economy Is Needed to Prepare for Future Global Crises, Chatham House, available at: https:/www.chathamhouse.org/expert/comment/why-inclusivecircular-economy-needed-prepare-future-global-crises (accessed 6 September 2020).

SEMI (2020), “About semi”, available at: https:/www.semi.org/en/about (accessed 25 May 2020).

Sundram, V.P.K., Bahrin, A.S., Minur, Z.B.A. and Zolait, A.H. (2018), "The effect of supply chain information management and information system infrastructure", Journal of Enterprise Information Management, Vol. 31 No. 5, pp. 751-770.

Urbański, M., Haque, A.U., Lang, J. and Kozlovski, E. (2020), "The impact of total quality management and business networks on company export performance in emerging vs developed economies: evidence from furniture enterprises in Pakistan and the UK", European Journal of International Management. doi: 10.1504/EJIM.2021.10033182.

$\mathrm{Xu}, \mathrm{X}$. (2012), "From cloud computing to cloud manufacturing", Robotics and Computer-Integrated Manufacturing, Vol. 28 No. 1, pp. 75-86.

\section{Further reading}

Campbell, B.M., Hansen, J., Rioux, J., Stirling, C.M. and Twomlow, S. (2018), "Urgent action to combat climate change and its impacts (SDG 13): transforming agriculture and food systems”, Current Opinion in Environmental Sustainability, Vol. 34, pp. 13-20. 